\title{
THE BEHAVIOR OF RADIOIODINE IN THE BLOOD ${ }^{1}$
}

\author{
By WILLIAM M. MCCONAHEY,2 F. RAYMOND KEATING, JR., \\ AND MARSCHELLE H. POWER \\ (From the Divisions of Medicine and Biochemistry, Mayo Clinic, Rochester, Minnesota)
}

(Received for publication July 10, 1948)

Radioiodine has been used to study the function of the human thyroid gland in various ways. The quantity of radioiodine collected by the thyroid has been determined directly by in vivo measurements (Hamilton, Soley and co-workers [14] ; Hertz and co-workers [5]), and indirectly by estimations from the total quantity excreted in the urine over a fixed period (Hertz and coworkers [5]; Rawson and co-workers [6, 7]). The distribution of iodine in the thyroid has been studied by autoradiograms (3) or by chemical analysis of excised tissue (5). Most recently the capacity of the thyroid to concentrate radioiodide has been studied by Stanley and Astwood (8) after previous administration of an antithyroid drug such as mercaptoimidazol.

Keating, Power, Berkson, and Haines (9) have employed radioiodine to investigate the kinetics of iodine metabolism. They studied the urinary excretion of radioiodine by collecting all the urine in short periods for three days or longer. By plotting cumulative urinary excretion against time, they obtained an exponential curve from which were estimated four quantities: (1) a renal fraction (that part of the dose of radioiodine primarily excreted in the urine); (2) a disappearance rate (which they inferred to represent the proportional rate of disappearance of radioiodine from the blood); (3) a renal excretion rate (the proportional rate of excretion into the urine); and (4) a so-called collection rate (the proportional rate of disappearance into other sites than the kidneys, of which the most important is the thyroid). The most significant measure of thyroid activity was the collection rate, which was much less than normal in hypothyroid

1 An abridgment of a portion of the thesis submitted by Dr. McConahey to the Faculty of the Graduate School of the University of Minnesota in partial fulfillment of the requirements for the degree of Master of Science in Medicine.

2 Fellow in Medicine, Mayo Foundation. patients and much greater than normal in hyperthyroid patients.

The present study was undertaken as an extension of the foregoing observations. Its objects were (1) to examine directly the behavior of radioiodine in blood after its oral administration to persons who had varying states of thyroid function; (2) to compare the disappearance rate of radioiodine in blood as determined directly from observations in the blood itself with estimates of this same value obtained from urinary studies in the manner previously described; and (3) to examine the appearance in the blood of organically bound radioiodine.

\section{PROCEDURES}

The subjects selected for study came to the laboratory without breakfast. After withdrawal of a control sample of blood, radioiodine ( $\mathrm{I}^{131}$, Oak Ridge Laboratories, A. E. C.), in the form of sodium iodide dissolved in about $150 \mathrm{cc}$. of water containing $100 \mu \mathrm{g}$. of nonradioactive sodium iodide, was given by mouth. Samples of blood and urine were thereafter collected at stated intervals. The quantity of radioiodine present in these specimens was estimated by means of a Geiger-Müller counting tube with thin mica window in connection with a suitable scaling circuit. All counts were corrected for "background," which was uniformly about 0.5 count per second or less. Appropriate aliquots of each dose given were reserved as standards, each of which was counted simultaneously with its corresponding blood and urine samples. The method of preparing urine for counting has been described (Keating and co-workers [9]). The blood samples were allowed to clot at room temperature and, after the separation of the serum by centrifugation, were analyzed for radioactivity as described in the next section.

Total radioactivity of serum. The counting of films of serum dried directly on thin copper disks was unsatisfactory. However, after partial alkaline hydrolysis dry films suitable for counting could be obtained. One cc. of serum in a pyrex test tube $7 \mathrm{~mm}$. (internal diameter) by $100 \mathrm{~mm}$. was thoroughly mixed with $0.100 \mathrm{cc}$. of 2.5 $\mathrm{N}$ solution of sodium hydroxide. The tube was covered with a small pyrex cup and heated for 30 minutes at 10 to 15 pounds in a pressure cooker. This treatment caused little or no change in volume. Some sediment which 
formed was carefully resuspended by shaking, although later studies showed that little or no error was introduced by failure to resuspend this sediment. Samples of the alkaline digest were measured out for radioactivity analysis, by means of a syringe pipet calibrated to deliver $0.200 \mathrm{cc}$. In order to prevent accumulation of radioiodine in this pipet, which might then cause error in future samples, it was rinsed between measurements with 10 portions of strong solution of potassium iodide followed by 10 portions of water. Finally two portions of the digest to be examined were drawn in and discarded, then duplicate $0.200 \mathrm{cc}$. samples were transferred to copper disks 1 inch $(2.5 \mathrm{~cm}$.) in diameter. The samples were dried slowly under an infra-red lamp, cooled, and counted immediately thereafter, in order to avoid variations attendant on the possible absorption of moisture by the dry alkaline films. The counts observed, corrected for background as mentioned previously, were converted to counts per second per unit volume and, by reference to the simultaneously counted standard, to percentage of administered dose per liter of serum. Each planchet was counted at least twice, and usually enough counts were taken so that the variation due to randomness of atomic disintegration would be less than 5 per cent. Finally, a positive correction of 15 per cent was applied to all counts of serum digests, to compensate for losses due to "absorption" of beta rays by the deposit of alkali and partly degraded protein.

This correction factor was obtained as follows: To 34 samples of normal serum, each measuring $0.9 \mathrm{cc}$., were added $0.1 \mathrm{cc}$. of radioiodine of known radioactivity and $0.1 \mathrm{cc}$. of 10 per cent sodium hydroxide. The samples were heated in a pressure cooker and $0.2 \mathrm{cc}$. aliquots were prepared for dry counting on planchets as described previously. These were compared with planchets prepared from equal amounts of radioiodine in aqueous solution as standards. It was found that in the 34 samples, the mean loss of radioactivity by absorption was $15.2 \pm 0.5$ per cent with a range of 11.1 to 20.0 per cent.

In order to investigate the reproducibility of the method, blood was drawn from a hyperthyroid patient 24 hours after administration of 100 microcuries of $\mathrm{I}^{131}$. Ten samples of the serum, each of $1.0 \mathrm{cc}$, were analyzed for their radioactivity. The mean value obtained was 11.19 counts per second per cubic centimeter. The standard deviation for the determinations from the separate specimens of serum was 0.43 counts per second or about 4 per cent of the mean, which gives an estimate of the error of such determinations. Taking into consideration variations caused by "absorption," variations inherent in the counting equipment and errors introduced by chemical manipulation, it is estimated that the over-all experimental error of a single determination of radioiodine did not exceed 10 to 15 per cent.

Radioiodinc precipitated from scrum by protcin precipitants. This fraction, henceforth referred to as "precipitable" radioiodine, was separated by means of precipitation of proteins with the zinc sulfate-sodium hydroxide reagents of Somogyi $(10,11)$, as used by Man, Smirnow, Gildea and Peters (12) in their study of serum iodine fractions. In this procedure, $1 \mathrm{cc}$. of serum in a $15 \mathrm{cc}$. pyrex centrifuge tube calibrated in tenths was treated with $1.00 \mathrm{cc}$. of $0.75 \mathrm{~N}$ solution of sodium hydroxide and $8.00 \mathrm{cc}$. of 0.125 per cent zinc sulfate in $0.031 \mathrm{~N}$ solution of sulfuric acid. The mixture was stirred thoroughly with a thin glass rod and centrifuged for five minutes at 1,500 r.p.m., and the supernatant was removed by decantation. The tube was filled with distilled water, the protein precipitate was thoroughly dispersed by stirring with the glass rod and the tube was again centrifuged. The supernatant was again discarded and the washing procedure was repeated twice more. The precipitate was next dispersed by stirring with $0.50 \mathrm{cc}$. of $2.5 \mathrm{~N}$ sodium hydroxide. The stirring rod was rinsed with two drops of water, and the alkaline mixture was autoclaved as in the determination of total radioiodine. After removal of the tube from the cooker, the volume of the digest was noted, and $0.200 \mathrm{cc}$. samples were measured out, dried and counted, as previously described. "Absorption" losses in this method of determining serum precipitable radioiodine were about the same as those noted in the determination of total radioactivity (actually the mean loss of 15 samples was 15.7 \pm 0.6 per cent). Control experiments in which radioiodine was added to serum showed that all but 0.25 to 2.9 per cent of added radioactivity was removed by the precipitation and washing technic.

An estimate of the error of the method for serum precipitable radioiodine was obtained in the following manner: ten $1.0 \mathrm{cc}$. samples of serum from blood which had been withdrawn from a hyperthyroid patient 24 hours after oral ingestion of a tracer dose were analyzed for serum precipitable radioiodine. The mean value obtained was 2.13 counts per second per cubic centimeter and the standard deviation for the determination from the separate serum specimens was 0.36 counts per second or about 17 per cent of the mean.

Miller and associates (13) found that exchange occurred in itro between inorganic and organic iodine compounds under certain conditions of $\mathrm{pH}$ and temperature. The possibility that similar exchange might account for some of the precipitable radioiodine observed with the method which we employed was investigated in the following manner. Radioiodine as iodide was added to each of eight tubes containing $1.0 \mathrm{cc}$. of normal human serum. Four tubes were stored at room temperature, and four were incubated at body temperature. One specimen from each group was analyzed for serum precipitable radioiodine after four, six, eight and 13 days, respectively. The quantity of radioiodine remaining in the precipitable fraction after washing was negligible ( 0.2 to 1.5 per cent of the total radioiodine present in the whole serum). On the basis of these observations it was felt that exchange could not account for any significant proportion of the precipitable radioiodine observed.

Thirty-one persons who had various thyroid conditions consented to be studied; 28 of these were patients being treated for thyroid disease and three were normal subjects. Serial blood levels of total radioiodine were determined in all 31 persons. Table I shows the functional 
TABLE I

Types of persons studied and the variations of the basal metabolic rate

\begin{tabular}{|c|c|c|}
\hline States of thyroid & Cases & $\underset{\substack{\text { Basal } \\
\text { rabole }}}{\text { metabolic }}$ \\
\hline $\begin{array}{l}\text { Hyperthyroidism } \\
\text { Exophthalmic goiter }\end{array}$ & $\begin{array}{l}17 \\
16\end{array}$ & per cent \\
\hline $\begin{array}{l}\text { Primary } \\
\text { Recurrent }\end{array}$ & $\begin{array}{r}5 \\
11\end{array}$ & $\begin{array}{l}+40 \text { to }+53 \\
+15 \text { to }+60\end{array}$ \\
\hline $\begin{array}{l}\text { Adenomatous goiter with } \\
\text { hyperthyroidism }\end{array}$ & 1 & +21 \\
\hline $\begin{array}{l}\text { Euthyroidism } \\
\text { Normal subjects } \\
\text { Adenomatous goiter with- } \\
\text { out hyperthyroidism } \\
\text { Carcinoma of thyroid }\end{array}$ & $\begin{array}{l}9 \\
3 \\
4 \\
2 *\end{array}$ & $\begin{array}{c}\text { Not done } \\
-14 \text { to }+5 \\
-4\end{array}$ \\
\hline Hypothyroidism (myxedema) & $6^{*}$ & -36 to -11 \\
\hline
\end{tabular}

* One patient who had carcinoma of the thyroid was studied twice-once while he was in a euthyroid state and once while he was myxedematous as a result of a "thyroidectomizing dose" of $I^{181}$

state of the thyroid and basal metabolic rates of the patients studied. Seventeen had hyperthyroidism, nine were euthyroid and six had myxedema. One patient who had carcinoma of the thyroid was studied twice-once while his thyroid function was normal and later while myxedema was present as a result of a "thyroidectomizing dose" of $\mathrm{I}^{131}$. By a euthyroid person is meant one whose tissues at large receive the normal amount of thyroid hormone daily irrespective of the anatomic state of the thyroid gland.

Of the 36 doses of I131 given, 21 were tracer and 15 were therapeutic doses. The tracer dose used in most cases was 100 microcuries, although a few patients received more. A therapeutic dose is here defined as one large enough to destroy thyroid tissue by radiation. Comparison of tracer doses with subsequent therapeutic doses in the same patient did not disclose consistent or significant differences which could be ascribed to radiation effect within the 48-hour period when most observations were made. This does not exclude the possibility that radiation effects may have been present in either the tracer or the therapeutic doses, but it appears reasonable to assume that any effects of radiation present in the data are of small magnitude.

The use of $100 \mu \mathrm{g}$. of sodium iodide as carrier in these studies theoretically introduces an error in the tracer character of the experiments. It may be calculated that in the average person this quantity of iodide in equilibrium with the blood and extracellular fluids represents an initial increase in the concentration of iodide of the order of $0.5 \mu \mathrm{g}$. per $100 \mathrm{cc}$. of plasma. We have compared studies conducted with $100 \mu \mathrm{g}$. of carrier with studies employing carrier-free radioiodide as well as studies involving a carrier of 1 to $10 \mu \mathrm{g}$. Such observations indicate that the use of $100 \mu \mathrm{g}$. of sodium iodide as carrier does not affect the results observed either qualitatively or quantitatively to any significant degree.

\section{RESULTS}

Total radioiodine in blood serum. Radioiodine appeared in the circulating blood within a few minutes after oral administration. The concentration of radioiodine rose rapidly and reached a maximal level within one-half to one and onehalf hours after ingestion, the time at which the
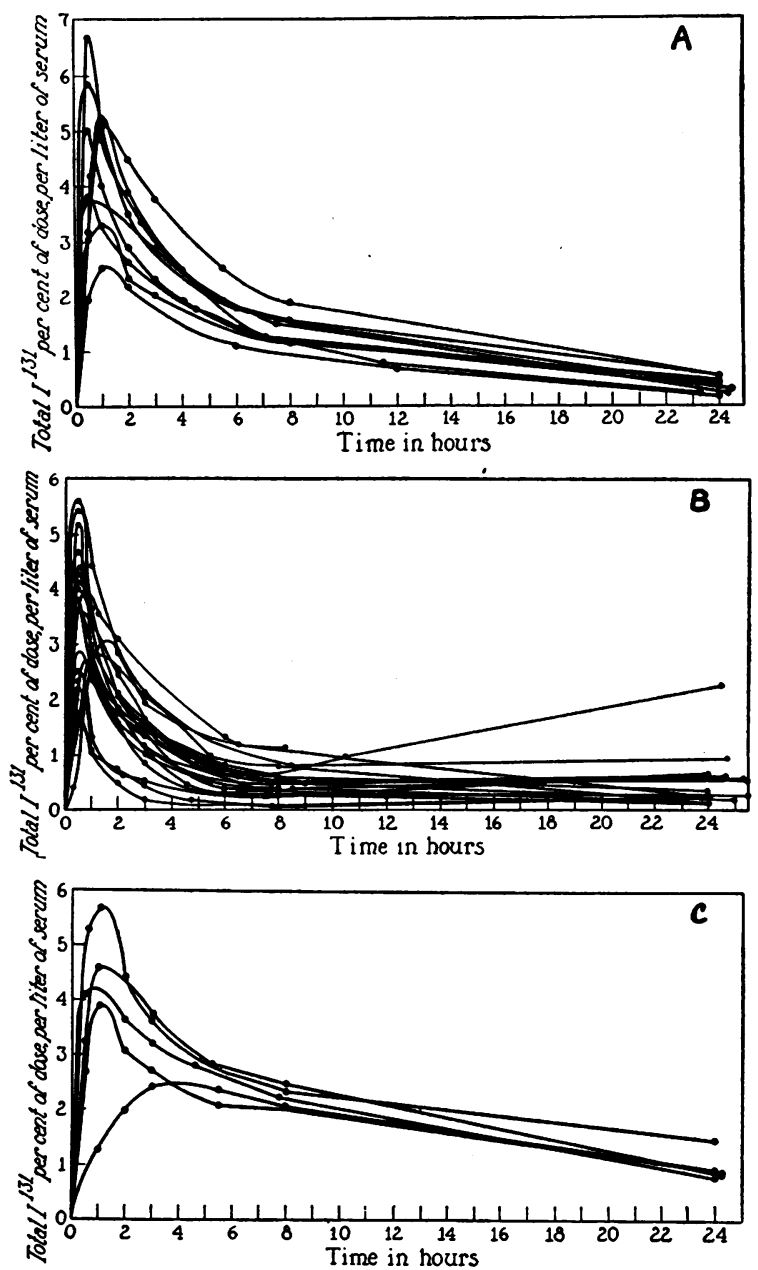

Fig. 1. The Concentration of Total Radioiodine in the Serum of Persons Who Had $(A)$ Normal Thyroid Function, ( $B$ ) Hyperthyroidism AND $(C)$ MYXedema

The group who had normal thyroid function includes three normal persons, four patients who had adenomatous goiter without hyperthyroidism, and two patients who had low grade nonfunctioning carcinomas of the thyroid. 
maximum level was attained varying somewhat with the functional state of the thyroid. Thereafter, the concentration diminished at a rate which was related to the functional state of the thyroid. Figure 1 shows the individual curves for the concentration of radioiodine in serum during the first 24 hours in all cases of the three groups studied. Figure 2 shows average curves for each of the three groups. In euthyroid patients, the concentration of radioiodine in the blood reached a maximal level between one-half and one hour and then fell for the rest of the 24 hours. In hyperthyroid patients, the concentration reached a maximal level sooner, usually in about one-half hour, then fell more rapidly than in the normals for six or eight hours, and thereafter decreased very slowly in some cases, leveled off in others, and in a considerable number again rose a second time from the low value observed at about eight hours after the dose. In patients who had hypothyroidism, a maximal level was reached later, usually between one, and one and one-half hours, and the level thereafter diminished more gradually than in euthyroid persons. Since, as is well known, both hyperthyroidism and myxedema affect the volume of both plasma and extracellular fluid, it is apparent that these data must be modified to some extent by such factors. Accurate evaluation of these factors would be possible only if both blood volume and volume of extracellular fluid had been measured in each individual case, a procedure which we were unable to follow in this study. Fortunately it appears probable that

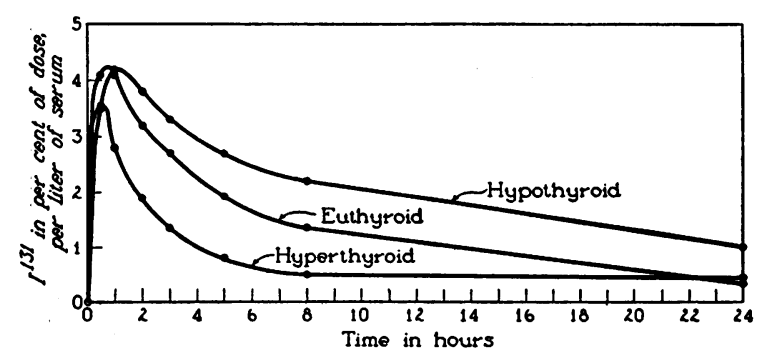

Fig. 2. Composite Curves of the Concentration of Total Radioiodine in the Serum in Various ThyRoID STates

Constructed from the mean concentrations for each group versus time. (From McConahey, W. M., Keating, F. R., Jr., and Power, M. H., The behavior of radioiodine in the blood in various thyroid states. Tr. Am. A. Study Goiter [In press].)

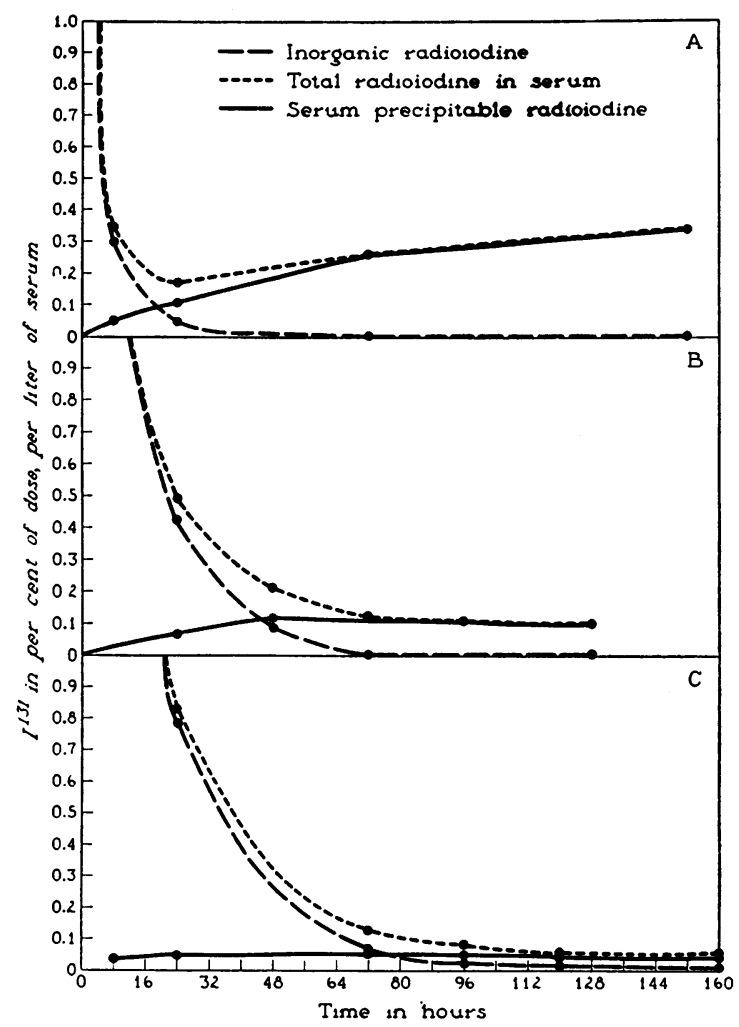

Fig. 3. Separation of the Concentration of Total Radioiodine in Serum into a Serum Precipitable Fraction aNd an InORganic Fraction

The latter was obtained by subtracting precipitable radioiodine from total radioiodine. $(A)$ A case of hyperthyroidism. (B) A person who had normal thyroid function. (C) A case of myxedema.

changes in blood volume and the volume of extracellular fluid accompanying various levels of thyroid activity were relatively minor factors in the differences which we observed.

Serum precipitable radioiodine. Levels of precipitable radioiodine in serum were determined in 13 cases (nine hyperthyroid, one myxedematous, and three euthyroid patients). Since it was not possible with the technics employed to measure precipitable radioiodine in the blood with accuracy after the administration of a small tracer dose, only persons who had received larger doses of radioiodine were studied in this manner. The doses of $I^{181}$ administered ranged from 1 to 100 millicuries. The results of this portion of the study may, therefore, have been affected by the consequences of radiation, but one may be justified in assuming that the results observed corre- 
spond at least qualitatively to physiologic conditions.

Figure 3A shows the values for serum precipitable radioiodine plotted as percentage of dose per liter of serum for a case of hyperthyroidism. The curve of total radioiodine in the serum is broken into two fractions: the one of serum precipitable radioiodine and the other of inorganic radioiodide obtained by subtracting values for precipitable radioiodine from total radioiodine. In Figure 3B are plotted the corresponding data in a patient who had normal thyroid function. Serum precipitable iodine appeared more rapidly and in larger concentrations in the hyperthyroid patient than in euthyroid persons and this fact appears to account for the leveling off or for the secondary rise in the curve of total radioiodine in serum observed in hyperthyroid cases. Figure $3 \mathrm{C}$ shows total radioiodine concentration and the inorganic and serum precipitable fractions, in a myxedematous patient. Inorganic iodide falls more slowly and precipitable iodine reaches a smaller concentration than in normal persons. In hyperthyroid subjects apparently all of the circulating radioiodine was precipitable after a period which averaged about 48 hours (Figure 4). In euthyroid subjects the average time re-

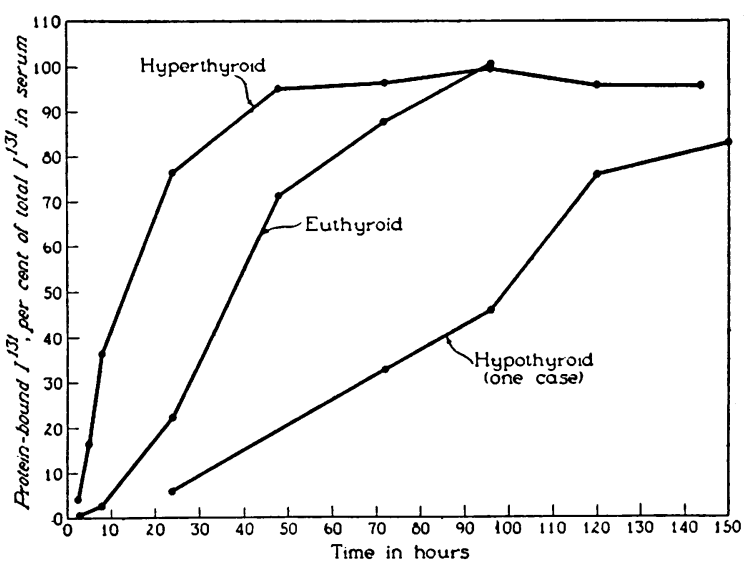

Fig. 4. Serum Precipitable Radioiodine in Various States of Thyroid Function

Each curve is constructed from the mean values of the cases comprising the group versus time; the value expressed is the percentage of the total radioiodine in serum which is precipitable. (From McConahey, W. M., Keating, F. R., Jr., and Power, M. H., The behavior of radioiodine in the blood in various thyroid states. $\mathrm{Tr}$. Am. A. Study of Goiter [In press].) quired for all circulating radioiodine to become precipitable was about 96 hours, and in the myxedematous subject this time was 290 hours. The foregoing results do not preclude the possibility that a small inorganic fraction might persist in any case for a longer time since the method employed for measuring precipitable radioiodine was relatively insensitive.

\section{COMMENT}

Figure 1 shows considerable variability of the curves of total radioiodine concentration in serum during the first six hours. Overlapping by members of the different groups is at a minimum at eight hours. In myxedema the concentration of radioiodine exceeded 2 per cent of the dose per liter of serum (from 2 to 2.5 per cent) at eight hours. The euthyroid and hyperthyroid curves overlapped a little at this time ( 1 to 1.9 per cent and 0.05 to 1.2 per cent, respectively), but the curves of neither group overlapped those of the cases of myxedema. Only one of the euthyroid curves was less than 1.2 per cent and only two of the hyperthyroid curves were more than 1 per cent.

Examination of the curve of concentration of total radioiodine in serum during the first 24 hours discloses at least three components: (1) a rapid rise to a maximal concentration and a brief, rapid fall; (2) a more prolonged fall at an exponential rate, and (3) a continued but much slower fall (or sometimes, in case of hyperthyroidism, a secondary slow rise to a higher level). Component 1 appears to reflect absorption from the gastro-intestinal tract and establishment of equilibrium between the blood and the body fluids; component 2 represents the disappearance of radioiodine as inorganic iodide from the blood and the body fluids into the urine, the thyroid and other sites of disposal; component 3 reflects in part the appearance in the blood of precipitable (that is, organically bound) radioiodine.

Keating and co-workers estimated the disappearance rate of radioiodine from the blood from the curve of excretion in the urine. The disappearance rate can be determined directly from the second component of the concentration curve of radioiodine in the blood. When the logarithm of 
concentration is plotted against time, the observations fit a straight line, the slope of which is the rate of disappearance of radioiodine from the blood.

The observations comprising component 3 fall above this straight line and in some hyperthyroid cases the period during which concentration of total radioiodine in blood fits an exponential function is rather short. If instead one plots the logarithm of inorganic radioiodine (estimated by difference as described) as ordinate, with time as abscissa, the points continue to fit an exponential function for a much longer period. This fact suggests that it is the inorganic iodide which disappears at an exponential rate and that it is the appearance of organically bound iodine which causes the curve of total radioiodine to deviate from an exponential curve.

TABLE II

Comparison of disappearance rate determined in blood and in urine

\begin{tabular}{|c|c|c|c|c|c|}
\hline & \multirow{2}{*}{ Cases } & \multicolumn{2}{|c|}{ Disappearance rate } & \multirow{2}{*}{ Difference } & \multirow{2}{*}{ P* } \\
\hline & & $\begin{array}{l}\text { Determined } \\
\text { from blood }\end{array}$ & $\begin{array}{l}\text { Determined } \\
\text { from urine }\end{array}$ & & \\
\hline $\begin{array}{l}\text { Euthyroid } \\
\text { Hyper- } \\
\text { thyroid } \\
\text { Hypo- } \\
\text { thyroid }\end{array}$ & $\begin{array}{r}9 \\
17 \\
6\end{array}$ & $\begin{array}{c}\text { per cent/hr. } \\
15.9 \pm 1.1 \dagger \\
40.2 \pm 4.6 \\
8.8 \pm 0.9\end{array}$ & $\begin{array}{c}\text { per cent } / \mathrm{hr} . \\
15.0 \pm 0.8 \\
37.0 \pm 4.7 \\
\\
6.4 \pm 0.6\end{array}$ & $\begin{array}{r}\text { per cent/hr. } \\
-0.9 \pm 1.3 \\
-3.2 \pm 2.7 \\
-2.4 \pm 0.8\end{array}$ & $\begin{array}{l}0.2 \\
0.04\end{array}$ \\
\hline
\end{tabular}

* $P$ values obtained from Table of $T, R$. A. Fisher, Statistical Methods for Research Workers, Seventh Edition, Oliver and Boyd, 1938.

$\dagger$ The values given are the means and standard errors of the means.

In Table II the mean disappearance rates of radioiodine from blood for each group, calculated directly from observations on the blood, are compared with the values obtained from simultaneous observations on the urine of each subject calculated in the manner described by Keating and co-workers. The means of the individual differences, which are also given, do not appear to be significant, and may reflect merely the errors of the methods employed. It seems, therefore, that the disappearance rate of radioiodine from blood measured by either method reflects variations in thyroidal function with respect to iodine collection. However, since radioiodine disappears from blood into the urine, and also into other tissues in addition to the thyroid, disappearance rate is not a direct or quantitative measure of thyroidal accumulation of iodine. This is evidenced by the values for disappearance rate in cases of myxedema, in most of which accumulation of radioiodine by the thyroid was found by in vivo measurements to be negligible or absent.

The appearance of precipitable radioiodine in blood can be construed as largely representing radioiodine collected by the thyroid, synthesized into organic compounds and secreted into the circulation. Determinations of precipitable radioiodine reflect variations in thyroid function in several ways : 1 . The concentrations of precipitable radioiodine reached in cases of hyperthyroidism are greater than in cases of euthyroidism. 2. Precipitable radioiodine can be detected sooner in hyperthyroid cases than in euthyroid cases and the concentration increases at a more rapid rate. 3. Estimation of precipitable radioiodine as a percentage of total serum radioiodine reflects both the foregoing and the differences in the behavior of inorganic iodide with variations in thyroidal function, so that precipitable radioiodine replaces the inorganic fraction much more rapidly than normal in hyperthyroid subjects and much less rapidly than normal in hypothyroid subjects. These relationships are entirely consistent with what is known about the behavior of chemically determined precipitable iodine in persons who have varying states of thyroidal activity.

It is surprising and a little disturbing to note the appearance of precipitable radioiodine in the single case of myxedema in which this determination was made (Figures $3 \mathrm{C}$ and 4 ). The patient was a young man having carcinoma of the thyroid who some months previously had been made myxedematous by means of a "thyroidectomizing" dose of radioiodine. The concentration of precipitable radioiodine observed in this case was small, and this concentration was substantially achieved within a few hours (Figure 3C). The survival of some thyroid tissue cannot be excluded, although no detectable collection occurred in the thyroid region and the basal metabolic rate was -25 per cent. The possibility of in vivo exchange occurring in the blood remains a remote possibility but such exchange could not 
be demonstrated in vitro. The observations of precipitable radioiodine in this case may be of some interest in connection with the demonstration by Chapman (14) and by Morton and associates (15) that iodine may be organically combined elsewhere in the body than in the thyroid.

The method employed here to estimate concentration of precipitable radioiodine is relatively insensitive and relatively inaccurate. On this account and because of the possibility of distortion by the quantities of radiation involved it appears unwise to attempt to analyze quantitatively the kinetic behavior of organically bound radioiodine from these data. It appears likely, however, that with more sensitive and accurate methods of analysis the rate of increase of organically bound radioiodine in blood and the maximal concentration achieved can be compared with the concentration of protein-bound iodine measured by chemical methods in order to obtain a measure of turnover rate of protein-bound iodine.

\section{SUMMARY AND CONCLUSIONS}

1. Levels of total radioiodine in the blood after oral ingestion of $\mathrm{I}^{131}$ in the form of iodide show significant differences in various thyroid states. Eight hours after ingestion, mean concentration of radioiodine in the serum was 2.06 per cent of the dose per liter in cases of myxedema, 1.28 per cent in euthyroid persons and 0.49 per cent in cases of hyperthyroidism.

2. The curve of total radioiodine in serum plotted against time has three components: (a) an initial rapid increase followed by a brief, rapid fall, regarded as reflecting gastro-intestinal absorption and equilibration with body fluids; $(b)$ an exponential fall, regarded as reflecting disappearance of radioiodine as iodide from the blood into the thyroid, the urine and other sites of disposal, and (c) a third phase which indicates the appearance in the blood of organically bound radioiodine.

3. The rate of disappearance of radioiodine from the blood reflects variations in thyroidal function, being more rapid than normal in hyperthyroid subjects and less rapid than normal in hypothyroid ones.

4. Comparison of the rate of disappearance. of radioiodine from blood estimated directly from blood itself with estimations of the same rate determined from simultaneous observations of urinary excretion of radioiodine did not disclose any significant difference. The latter method therefore appears to be an appropriate means of estimating the disappearance rate of radioiodine from blood.

5. Precipitable radioiodine appeared in the blood much sooner, rose more rapidly and reached higher concentrations in hyperthyroid than in euthyroid persons. A small concentration of precipitable radioiodine was observed in a patient who had myxedema.

\section{BIBLIOGRAPHY}

1. Hamilton, J. G., and Soley, M. H., Studies in iodine metabolism by the use of a new radioactive isotope of iodine. Am. J. Physiol., 1939, 127, 557.

2. Hamilton, J. G., and Soley, M. H., Studies in iodine metabolism of the thyroid gland in situ by the use of radio-iodine in normal subjects and in patients with various types of goiter. Am. J. Physiol., 1940, 131, 135.

3. Hamilton, J. G., Soley, M. H., and Eichorn, K. B., Deposition of radioactive iodine in human thyroid tissue. Univ. California Publ., Pharmacol., 1940, $1,339$.

4. Hamilton, J. G., Soley, M. H., Reilly, W. A., and Eichorn, K. B., Radioactive iodine studies in childhood hypothyroidism. Am. J. Dis. Child., 1943, 66, 495.

5. Hertz, S., Roberts, A., and Salter, W. T., Radioactive iodine as an indicator in thyroid physiology. IV. The metabolism of iodine in Graves' disease. J. Clin. Invest., 1942, 21, 25.

6. Rawson, R. W., Evans, R. D., Means, J. H., Peacock, W. C., Lerman, J., and Cortell, R. E., The action of thiouracil upon the thyroid gland in Graves' disease. J. Clin. Endocrinol., 1944, 4, 1.

7. Rawson, R. W., Moore, F. D., Peacock, Wendell, Means, J. H., Cope, Oliver, and Riddell, C. B., Effect of iodine on the thyroid gland in Graves' disease when given in conjunction with thiouracil -a two-action theory of iodine. J. Clin. Invest., 1945, 24, 869.

8. Stanley, M. M., and Astwood, E. B., The accumulation of radioactive iodide by the thyroid gland in normal and thyrotoxic subjects and the effect of thiocyanate on its discharge. Endocrinology, 1948, 42, 107.

9. Keating, F. R., Jr., Power, M. H., Berkson, Joseph, and Haines, S. F., The urinary excretion of radioiodine in various thyroid states. J. Clin. Invest., 1947, 26, 1138. 
10. Somogyi, Michael, A method for the preparation of blood filtrates for analysis. Proc. Soc. Exper. Biol. \& Med., 1929, 26, 353.

11. Somogyi, Michael, A method for the preparation of blood filtrates for the determination of sugar. J. Biol. Chem., 1930, 86, 655.

12. Man, E. B., Smirnow, A. E., Gildea, E. F., and Peters, J. P., Serum iodine fractions in hyperthyroidism. J. Clin. Invest., 1942, 21, 773.

13. Miller, W. H., Anderson, G. W., Madison, R. K., and Salley, D. J., Exchange reactions of diiodotyrosine. Science, 1944, 100, 340.

14. Chapman, Asher, Extrathyroidal iodine metabolism. Endocrinology, 1941, 29, 686.

15. Morton, M. E., Chaikoff, I. L., Reinhardt, W. O., and Anderson, Evelyn, Radioactive iodine as an indicator of the metabolism of iodine. VI. The formation of thyroxine and diiodotyrosine by the completely thyroidectomized animal. J. Biol. Chem., 1943, 147, 757. 